\title{
Melatonin, placental growth factor and placental hormones at placental insufficiency
}

\author{
Berbets A. ${ }^{1}$, Konkov D. ${ }^{2}$, Bulavenko O. ${ }^{2}$, Taran O. ${ }^{2}$, Bakun O. ${ }^{1}$ \\ ${ }^{1}$ Bukovinian State Medical University, Chernivtsi, Ukraine \\ ${ }^{2}$ National Pirogov Memorial Medical University, Vinnytsya, Ukraine \\ e-mail: andriy.berbets@gmail.com
}

\section{ABSTRACT}

A pineal gland attracts much attention of scientists lately, because it secrets melatonin, which is a very important hormone. Melatonin plays a significant role in the development of pregnancy: it enhances implantation, decreases oxidative stress etc. At the same time, the links between the pineal gland and the placenta, as a part of endocrine system of a mother, are still not well described.

OBJECTIVE OF THE STUDY. To investigate the pathogenic links between secretion of melatonin, placental growth factor and reproductive hormones in pregnant women with placental insufficiency, manifested as intrauterine fetal growth restriction.

MATERIAL AND METHODS. 35 pregnant women aged 18-36 with placental insufficiency (PI) were examined (study group). The placental insufficiency manifested as the intrauterine fetal growth restriction (IUGR) in the $3^{\text {rd }}$ pregnancy trimester. The control group consisted of 20 women with uncomplicated pregnancy at the same term. The blood concentrations of melatonin and placental growth factor (PIGF) were studied, as well as the blood concentrations of certain placental hormones: progesterone, placental lactogen and unconjugated estriol.

RESULTS. The concentration of melatonin was found to decrease significantly, if pregnancy was complicated by intrauterine fetal growth retardation (study group - $129.90 \pm 17.65 \mathrm{pg} / \mathrm{ml}$, control group $-231.25 \pm 21.56 \mathrm{pg} / \mathrm{ml}, p<0.01$ ), as well as concentration of PIGF (study group $130.78 \pm 15.80 \mathrm{pg} / \mathrm{ml}$, control group $-230.0 \pm 29.97 \mathrm{pg} / \mathrm{ml}, p<0.01$ ). A significant difference of progesterone concentrations between the groups was found (study group: $15.36 \pm 2.78 \mathrm{ng} / \mathrm{ml}$, control group: $30.43 \pm 2.66 \mathrm{ng} / \mathrm{ml}, p<0.01$ ), as well as for placental lactogen (study group: $6.31 \pm 2.08 \mathrm{mg} / \mathrm{l}$, control group: $7.76 \pm 1.93 \mathrm{mg} / \mathrm{l}, p<0.05)$. No significant difference between the concentrations of unconjugated estriol was found. A close correlation between melatonin and progesterone in the control group was found ( $r=0.76, P=0.0001)$, a moderate correlation between melatonin and unconjugated estriol was also established in the control group $(r=0.61, P=0.004)$, and a moderate negative correlation between melatonin and placental lactogen was found in the study group $(r=-0.438, P=0.042)$.

CONCLUSIONS. The blood levels of melatonin and PIGF significantly decrease in case of placental insufficiency, manifested as intrauterine fetal growth restriction syndrome. In healthy pregnant women, the secretion of steroid hormones (progesterone and unconjugated estriol) by placenta directly correlates with blood concentration of melatonin. This link is being disordered in case of placental insufficiency.

KEY WORDS: placental insufficiency, melatonin, placental growth factor, progesterone, placental lactogen, unconjugated estriol

At the present stage of the development of Obstetrics and Gynecology it has been commonly admitted that a favorable clinical course of pregnancy, as well as its outcome, directly depends on the condition of mother's health, especially of her endocrine system. The pineal gland (epiphysis) is one of the most important parts of this system. The endocrine function of this gland is producing and secreting of such hormones as melatonin and serotonin. Melatonin (5-methoxy- $\mathrm{N}$-acetyltriptamine) chemically belongs to the class of indols. The essential aminoacid tryptophan is the biological melatonin precursor. Unlike serotonin, melatonin easily crosses hemato-encephalic barrier [1, 2]. There is an assumption that this hormone is being secreted from the pineal gland into cerebrospi- nal fluid [3]. It's been established that melatonin is actively produced by trophoblact and placenta $[3,5]$ and plays an important role in the course of normal pregnancy: it is involved in successful implantation of a fertilized egg [3], has an influence on the childbirth [4], decreases oxidative stress [6], especially in the case of pre-eclampsia $[2,7,8]$ etc. Oral intake of melatonin improves the perinatal results in pregnant women with intrauterine fetal growth restriction (IUGR) [8]. At the same time, the interaction between the pineal gland and placental trophoblast as between the producers of melatonin as well as between the parts of endocrine system of a mother are still generally unclear. It is also unknown whether placenta secrets melatonin in circadian regime [8]. 
Placenta is an important organ in the context of the development of celIular transplantology because nowadays many researchers intensively study the possibilities of the use of stem cells in the therapy of different diseases; both umbilical blood [9] and placental tissue $[10,11]$ are proposed for this goal. It is still unclear whether the sampling of umbilical cord's blood and/or placental tissue for stem cells isolation is reasonable or not in case of diagnosed placental insufficiency and IUGR, and what are the relevant risks. For example, one of such risks might be the mitochondrial insufficiency of the trophoblast's stem cells caused by hypoxic stress [12]. Therefore, the new markers (mostly biochemical) that could depict the conditions of placenta's tissue and cells are being intensively searched.

Among others, Placental Growth Factor (PIGF) can be considered as such a marker. PIGF expresses pro-angiogenic effect in maternal-fetal complex; it also has positive influence on the growth of trophoblast, and it has been well known as the predictor and the diagnostical marker of preeclampsia. $[13,14]$. On the other hand, lately this molecule attracts more attention of the researches in the case of placental insufficiency (PI) or fetal distress. For example, Bligh et al. established that the lowered level of PIGF in mothers 'blood is associated with the decreased Apgar score of newborns, pathological changes of the rhythm of the fetal heartbeat during labor and with the changes of the blood $\mathrm{pH}$ in the umbilical arteries which are usually observed in case of fetal hypoxia [15]. Kwiatkowski et al. found out that the ratio between PIGF and soluble FMS-like tyrosine kinase-1 (sFlt-1) is changed with the predominance of sFlt-1, if the blood flow disorders, expressed as «ischemic placental syndrome», are present in the uterine and umbilical arteries. The authors also have found the negative correlation between the concentrations of PIGF, studied in the blood plasma of pregnant women, and the degrees of the disorders of the blood flow in uterine and umbilical arteries [16]. Broere-Brown et al. studied relevantly large cohort of patients (3461 labors) and established that the decreased level of PIGF in umbilical blood sampled at labor has been associated with the lowered body mass at birth and with the presence of IUGR [17]. The presence of links between the decrease of PIGF and the expression of PI has also been confirmed by other researches $[18,19]$.

Based on the mentioned above, the conclusion can be drawn that the decreased level of PIGF both in the blood plasma of a pregnant woman and in umbilical blood is the reliable diagnostic criteria of PI and IUGR.

OBJECTIVE OF THE STUDY. To investigate the pathogenic links between secretion of melatonin, placental growth factor and reproductive hormones in pregnant women with placental insufficiency, manifested as the intrauterine fetal growth restriction.

\section{MATERIALS AND METHODS}

35 pregnant women aged 18-36 with placental insufficiency manifesting as IUGR syndrome of $2^{\text {nd }}$ to $3^{\text {rd }}$ degree of severity (the predicted body mass of the fetus was less then $10^{\text {th }}$ percentile, according to ultrasound examination) were included in the study (experimental) group at pregnancy term 30-36 weeks of gestation. The control group consisted of 20 women with uncomplicated pregnancy at the same term. The women suffering from severe extragenital pathology and also patients, who had been diagnosed with immune conflict or had the signs of intrauterine infection, were excluded from the study.

The blood concentrations of melatonin and placental growth factor (PIGF) as well as the blood concentrations of certain placental hormones (progesterone, placental lactogen and unconjugated estriol) were studied in venous blood. The blood was sampled by one-time veninpuncture of peripheral vein performed on fasting condition at $8 \mathrm{am}$. The samples were centrifuged for 5 minutes with acceleration $1000 \mathrm{xg}$. The concentrations of melatonin and PIGF were established by ELISA using diagnostic kits Melatonin ELISA and PIGF ELISA (IBL, Germany) and analyzer Stat Fax 1904 (Awareness Technology, Inc., USA).

We also established the concentrations of the hormones, produced by placenta (progesterone, unconjugated estriol and placental lactogen), in all women who were included to the study group and the control group. The determination of the levels of the reproductive hormones was performed by ELISA. The levels of placental lactogen were established using microplate reader URIT-660 (URIT Medical Electronic Group Co., Ltd, China People Republic). The concentrations of unconjugated estriol and progesterone in the blood plasma of the patients were studied by chemiluminescent immune assay. The diagnostic kits Siemens (Germany) were used for each hormone. The results were estimated using analyzer IMMULITE 2000 (Siemens Healthcare Diagnostics Inc., USA).

The results were statistically processed by software MedCalc (MedCalc Software, Belgium) using Welch-test for unequal samples. The data was represented as $\mathrm{M} \pm \mathrm{SD}$. The differences were considered as statistically significant in case of $p<0.05$. Pearson's coefficient of correlation was used for establishing the correlation links between studied indexes.

\section{RESULTS AND DISCUSSION}

The results of the study of the melatonin concentrations in the blood of examined women are represented on the Figure 1. The mean concentration of melatonin in the study group was found as $129.90 \pm 17.65 \mathrm{pg} / \mathrm{ml}$ $(\mathrm{n}=35)$, in the control group $-231.25 \pm 21.56 \mathrm{pg} / \mathrm{ml}(\mathrm{n}=20)$. According to the histogram, significantly lowered concentrations of melatonin were found in pregnant women with $\mathrm{PI}$, compared to the healthy pregnant women $(p=0.0003)$.

The results of the comparison of the levels of PIGF in the blood plasma of examined women are represented on the Figure 2 . The reduction of the mean concentration of PIGF by 1.78 times in the blood plasma of pregnant women of the study group, compared to the control group (study group $-130.78 \pm 15.80 \mathrm{pg} / \mathrm{ml}$, control group $-230.00 \pm 29.97 \mathrm{pg} / \mathrm{ml}$, $p<0.01$ ), in our opinion, is the evidence of the decline of angiogenesis in placental tissue.

Data of the levels of hormones that are produced by placenta (progesterone, unconjugated estriol, placental lactogen) are listed below (Table 1). Our results confirm the presence of $\mathrm{PI}$ in women of the experimental group, since we have found a significant decrease, compared to the control group, of two out of the three studied hormonal indicators of placental activity. The disordered hormonal activity of the placental tissue in the group of women with $\mathrm{PI}$ was expressed as the decrease of concentrations, compared to control, of progesterone (by 1.98 times, $p<0.01$ ), and placental lactogen (by 1.23 fold, $p<0.05$ ).

No significant difference was found between the concentrations of unconjugated estriol between the groups. This fact might be considered as the compensatory reaction of the placental tissue.

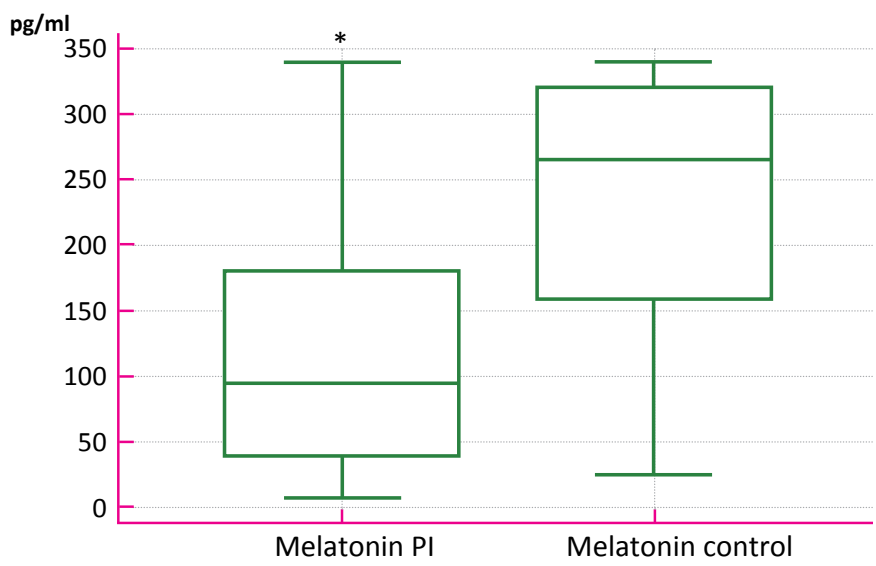

Fig. 1. The concentration of melatonin in the blood plasma of pregnant women with PI («Melatonin Pl», $\mathrm{n}=35$ ) and of pregnant women of the control group ( «Melatonin control», $\mathrm{n}=20$ ).

Note: ${ }^{*}-p<0.01$ compared to the control group. 


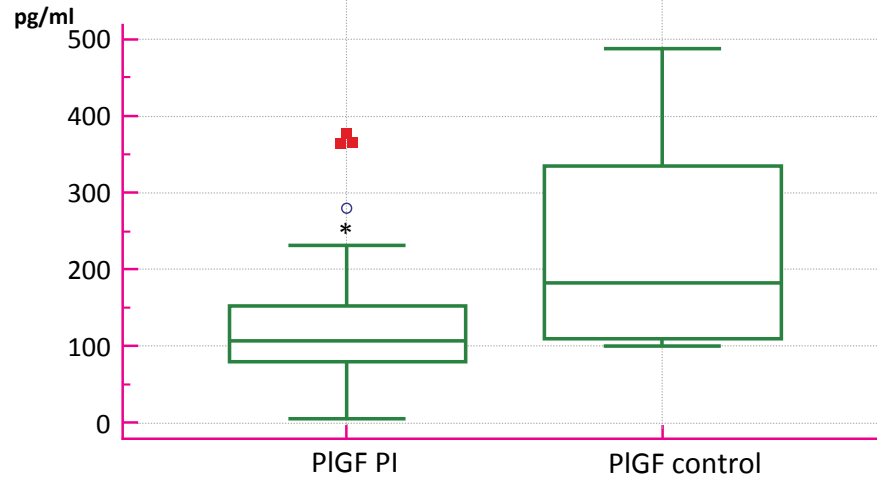

Fig. 2. The concentration of PIGF in the blood plasma of pregnant women with $\mathrm{PI}$ («PIGF PI», $n=35$ ) and pregnant women of the control group («PIGF control», $\mathrm{n}=20$ )

Note: ${ }^{*}-p<0.01$ compared to the control group.

We also studied the correlation links between studied indexes. In particular, a close correlation between melatonin and progesterone levels was found in the control group $(r=0.76, P=0.0001$; fig. 3$)$, as well as a moderate correlation between the concentrations of melatonin and unconjugated estriol - also in the control group $(r=0.61, P=0.004$; fig. 4).

In the group of women with $\mathrm{PI}$ we could only establish the moderate negative correlation between the levels of melatonin and placental lactogen ( $r=-0.438, P=0.042$; fig. 5 ).

Basing on the above data, it can be assumed that in healthy pregnant women the production of steroid hormones by placenta, namely progesterone and unconjugated estriol, directly depends on the concentration of melatonin in the blood. This correlation is disordered in the case of PI. Melatonin should be considered as a trigger for the detected correlation links, because it has been established that this hormone, in particular, affects the balance of estrogen sulfates in endothelial cells of the umbilical vein by regulating the balance between estrogen-sulfatase and sulfotransferase [20]. A similar principle of regulation might be relevant also to progesterone. Some researchers indicate the protective role of melatonin due to anti-oxidant activity in the production of progesterone by lutheal cells [21]. There are reasonable bases to affirm that melatonin also stimulates secretion of progesterone by placental tissue [22, 23].

Concerning placental lactogen and its interaction with melatonin, it has been only established that the concentration of this hormone in placental tissue of rats changes accordingly to circadian rhythms [24]. In our opinion, the negative correlation between melatonin and placental lactogen can be explained as compensatory reaction of placental tissue: the deficiency of production of one of the mentioned hormones (placental lactogen) is partially compensated by another one (melatonin).

Melatonin has a positive effect on mesenchymal stem cells both in vitro and in vivo [25]; this way its level can be considered as critical for a successful isolation of these cells from umbilical blood. Concerning PIGF, it has been established that this factor is produced by mesenchymal stem cells [26], therefore, in theory, PIGF might be a diagnostical marker of quantity and quality of such cells. Unfortunately, we could not find any publications in scientific research databases that describe the interaction between melatonin and PIGF, neither in normal pregnancy, nor in case of placental insufficiency.

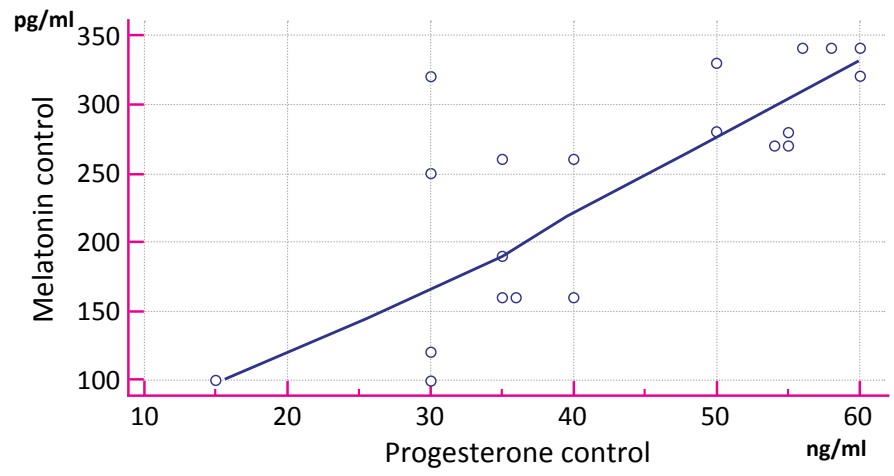

Fig. 3. Distributive correlative diagram depicting the correlation between the levels of melatonin and progesterone in the blood plasma of pregnant women of the control group.

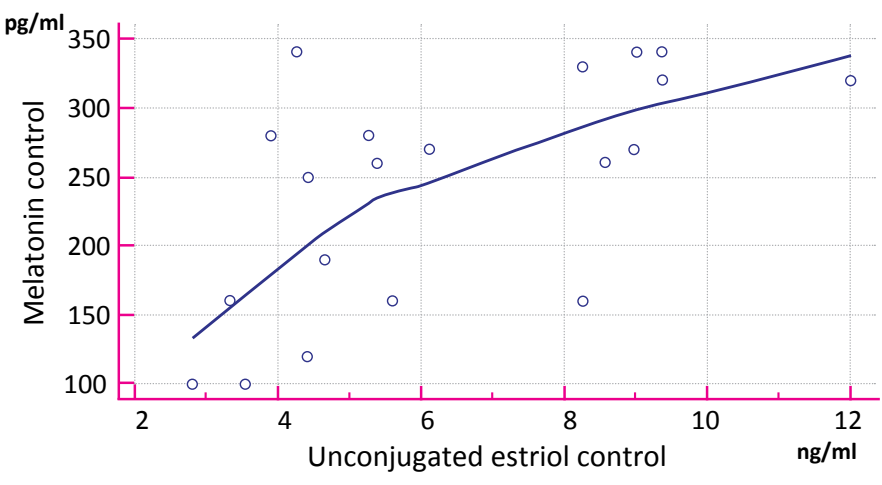

Fig. 4. Distributive correlative diagram depicting the correlation between the levels of melatonin and unconjugated estriol in the blood plasma of pregnant women of the control group.

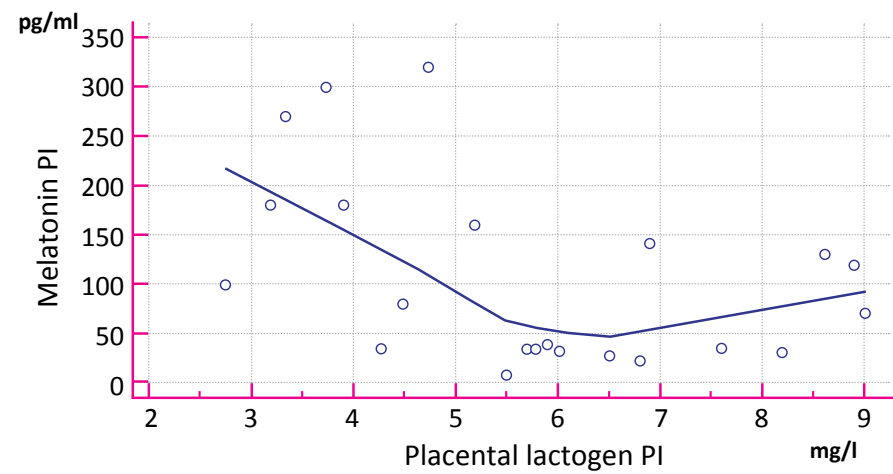

Fig. 5. Distributive correlative diagram depicting the correlation between the levels of melatonin and placental lactogen in the blood plasma of pregnant women with PI.
INDEX

PREGNANT WOMEN WITH PI

$$
(n=35)
$$

\section{Progesterone (ng/ml)}

Placental lactogen (mg/l)

Unconjugated estriol (ng/ml)
$15.36 \pm 2.78^{* *}$

$6.31 \pm 2.08^{*}$

$6.77 \pm 5.81$
PREGNANT WOMEN OF THE CONTROL GROUP $(n=20)$

$30.43 \pm 2.66$

$7.76 \pm 1.93$

$6.10 \pm 2.61$
Table 1. The levels of the reproductive hormones in the blood plasma of pregnant women of the studied groups

Notes:

$*-p<0,05$,

$* *-p<0,01$. 


\section{CONCLUSION}

To sum up, the blood levels of melatonin and PIGF in pregnant women significantly decrease in case of placental insufficiency, manifested as intrauterine fetal growth restriction syndrome. Placental insufficiency was confirmed biochemically in the study group, especially, a considerably decreased production of the placental hormones was found, compared to the pregnant women of the control group. In healthy pregnant women the secretion of steroid hormones (progesterone and unconjugated estriol) by placenta directly correlates with the blood concentration of melatonin. This link is disordered in case of placental insufficiency.

\section{REFERENCES}

1. Grishchenko VI. Rol' epifiza v fiziologii i patologii zhenskoy polovoy sistemy [Role of a pineal gland in physiology and pathology of woman's reproductive system]. Khar'kov: Vishcha shkola; 1979. 248 s. [in Russian].

2. Shimada M, Seki H, Samejima M, Hayase M, Shirai F. Salivary melatonin levels and sleep-wake rhythms in pregnant women with hypertensive and glucose metabolic disorders: A prospective analysis. BioSci Trends. 2016; 10(1):34-41. DOI: 10.5582/bst.2015.01123.

3. Soliman A, Lacasse A, Lanoix D, Sagrillo-Fagundes L, Boulard V, Vaillancourt C. Placental melatonin system is present throughout pregnancy and regulates villous trophoblast differentiation. J Pineal Res. 2015; 59(1):38-46. DOI: 10.1111/jpi.12236.

4. Takayama $\mathrm{H}$, Nakamura $Y$, Tamura $\mathrm{H}$. Pineal gland (melatonin) affects the parturition time but not luteal function and fetal growth, in pregnant rats. Endocr J. 2003; 50(1):37-43. DOl: 10.1507/endocrj.50.37.

5. Teixeira AA, Simoes MJ, Wanderley Teixeira V. Soares JJr. Evaluation of the implantation in pinealectomized and/or submitted to the constant illumination rats. Int J Morphol. 2004; 22(3):189-194.

6. Richter HG, Hansell JA, Raut Sh, Giussani DA. Melatonin improves placental efficiency and birth weight and increases the placental expression of antioxidant enzymes in undernourished pregnancy. J Pineal Res. 2009; 46:357-364. DOI: 10.1111/j.1600-079X.2009.00671.x.

7. Reiter RJ, Dun Xian Tan, Korkmaz A, Rosales-Corral SA. Melatonin and stable circadian rhythms optimize maternal, placental and fetal physiology. Hum Reprod Update. 2013; 20(2):293-307. DOI: 10.1093/humupd/dmt054.

8. Marseglia L, D'Angelo G, Manti S, Reiter RJ, Gitto E. Potential Utility of melatonin in preeclampsia, intrauterine fetal growth retardation, and perinatal asphyxia. Reprod Sci. 2016; 23(8):970-977. DOl: 10.1177/1933719115612132.

9. Sun C, Yue J, He N, Liu Y, Zhang X, Zhang Y. Fundamental Principles of Stem Cell Banking. Adv Exp Med Biol. 2016; 951:31-45. D0l: 10.1007/978-3-319-45457-3_3.

10. Teofili L, Silini AR, Bianchi M, Valentini CG, Parolini O. Incorporating placental tissue in cord blood banking for stem cell transplantation. Expert Rev Hematol. 2018 Aug; 11(8):649-661. DOl: 10.1080/17474086.2018.1483717.

11. Albanna MZ, Woods EJ. Fetal Stem Cell Banking. Stem Cell Biology and Regenerative Medicine. 2016; 295-316. D0I: 10.1007/978-1-4939-3483-6_16.

12. Xie Y, Zhou S, Jiang Z, Dai J, Puscheck EE, Lee I, et al. Hypoxic stress induces, but cannot sustain trophoblast stem cell differentiation to labyrinthine placenta due to mitochondrial insufficiency. Stem Cell Res. 2014; 13(3):478-91. DOI: 10.1016/j.scr.2014.07.007.

13. Bentona S, McCowan L, Heazell A, et al. Placental growth factor as a marker of fetal growth restriction caused by placental dysfunction. Placenta. 2016; 42:1-8. D0I: 10.1016/.placenta.2016.03.010.

14. Ong C, Liao A, Cacho A, et al. First-trimester maternal serum levels of placenta growth factor as predictor preeclampsia and fetal growth restriction. Am J Obstet Gynecol. 2001; 98(4):608-611. D0I: 10.1016/s0029-7844(01)01528-9.

15. Bligh $L N$, Greer RM, Kumar S. The relationship between maternal placental growth factor levels and intrapartum fetal compromise. Placenta. 2016; 48:63-67. D0I: 10.1016/j.placenta.2016.10.007.

16. Kwiatkowski S, Kwiatkowska E, Rzepka R, Dołegowska B, Torbe A, Bartosik-Sławińska A. Using Doppler ultrasound of the uterine and umbilical arteries and disordered angiogenesis markers (sFlt-1/PIGF) in unified monitoring of ischemic placental syndrome patients. Hypertens Pregnancy. 2016; 35(4):490-498. D0I: 10.1080/10641955.2016.1186688.

17. Broere-Brown ZA, Schalekamp-Timmermans S, Jaddoe VWV, Steegers EAP. Fetal Growth and Placental Growth Factor Umbilical Cord Blood Levels. Fetal Diagn Ther. 2018; 43(1):26-33. DOI: 10.1159/000475547.

18. Sherrell H, Dunn L, Clifton V, Kumar S. Systematic review of maternal Placental Growth Factor levels in late pregnancy as a predictor of adverse intrapartum and perinatal outcomes. Eur J Obstet Gynecol Reprod Biol. 2018; 225:26-34. DOl: 10.1016/j.ejogrb.2018.03.059.

19. Regnault TR, de Vrijer B, Galan HL, Davidsen ML, Trembler KA, Battaglia FC, et al. The relationship between transplacental 02 diffusion and placental expression of PIGF, VEGF and their receptors in a placental insufficiency model of fetal growth restriction. J Physiol. 2003; 15(550):641-56. D0l: 10.1113/jphysiol.2003.039511.

20. González A, Martínez-Campa C, Alonso-González C, Cos $S$. Melatonin affects the dynamic steady-state equilibrium of estrogen sulfates in human umbilical vein endothelial cells by regulating the balance between estrogen sulfatase and sulfotransferase. Int J Mol Med. 2015; 36: 1671-1676. D0l: 10.3892/jmm.2015.2360.

21. Taketani T, Tamura H, Takasaki A, Lee L, Kizuka F, Tamura I, et al. Protective role of melatonin in progesterone production by human luteal cells. J Pineal Res. 2011; 51:207-13. DOI: 10.1111/j.1600-079X.2011.00878.X.

22. Tamura H, Nakamura Y, Terron MP, Flores LJ, Manchester LC, Tan DX, et al. Melatonin and pregnancy in the human. Reprod Toxicol. 2008; 25(3):291-303. D0I: 10.1016/j.reprotox.2008.03.005.

23. Carlomagno G, Minini M, Tilotta M, Unfer V. From Implantation to Birth: Insight into Molecular Melatonin Functions. Int J Mol Sci. 2018; 19(9): 2802. DOI: 10.3390/ ijms19092802.

24. Valenzuela FJ, Vera J, Venegas C, Pino F, Lagunas C. Circadian System and Melatonin Hormone: Risk Factors for Complications during Pregnancy. Obstet Gynecol Int. 2015; 2015: 825802. DOI: 10.1155/2015/825802.

25. Hu C, Li L. Melatonin plays critical role in mesenchymal stem cell-based regenerative medicine in vitro and in vivo. Stem Cell Res Ther. 2019; 10:13. DOI: 10.1186/ s13287-018-1114-8

26. Dilogo IH, Fiolin, J, Aprianto P. Osteogenic Potency of Secretome Bone Marrow Derived Mesenchymal Stem Cells: A Literature Review. Adv Sci Let. 2018; 24(8): 6206-6208. DOI: 10.1166/asl.2018.12684. 


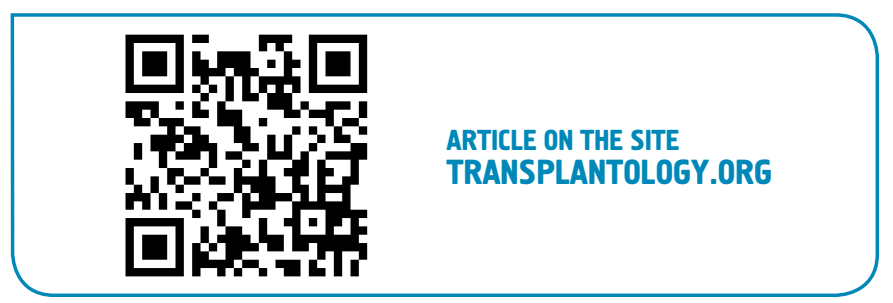

The authors declared no potential conflicts of interest with respect to the research, authorship, and/or publication of this article.

Received: October 04, 2019

Accepted: November 30, 2019 